\title{
Thallium-201 Imaging in Intact Olfactory Sensory Neurons with Reduced Pre-Synaptic Inhibition In Vivo
}

\author{
Hideaki Shiga ${ }^{1}$ (D) $\cdot$ Hiroshi Wakabayashi ${ }^{2} \cdot$ Kohshin Washiyama $^{3} \cdot$ Tomohiro Noguchi $^{4} \cdot$ Tomo Hiromasa $^{2} \cdot$ \\ Sadaharu Miyazono ${ }^{4} \cdot$ Masami Kumai $^{1} \cdot$ Kazuma Ogawa $^{5} \cdot$ Junichi Taki $^{2} \cdot$ Seigo Kinuya ${ }^{2} \cdot$ Takaki Miwa $^{1}$
}

Received: 20 May 2020 / Accepted: 14 August 2020 / Published online: 20 August 2020

(C) The Author(s) 2020

\begin{abstract}
In this study, we determined whether the ${ }^{201} \mathrm{Tl}$ (thallium-201)-based olfactory imaging is affected if olfactory sensory neurons received reduced pre-synaptic inhibition signals from dopaminergic interneurons in the olfactory bulb in vivo. The thallium-201 migration rate to the olfactory bulb and the number of action potentials of olfactory sensory neurons were assessed $3 \mathrm{~h}$ following left side nasal administration of rotenone, a mitochondrial respiratory chain complex I inhibitor that decreases the number of dopaminergic interneurons without damaging the olfactory sensory neurons in the olfactory bulb, in mice (6-7 animals per group). The migration rate of thallium-201 to the olfactory bulb was significantly increased following intranasal administration of thallium-201 and rotenone ( $10 \mu \mathrm{g}$ rotenone, $p=0.0012 ; 20 \mu \mathrm{g}$ rotenone, $p=0.0012)$, compared with that in control mice. The number of action potentials was significantly reduced in the olfactory sensory neurons in the rotenone treated side of $20 \mu \mathrm{g}$ rotenone-treated mice, compared with that in control mice $(p=0.0029)$. The migration rate of thallium- 201 to the olfactory bulb assessed with SPECT-CT was significantly increased in rats $24 \mathrm{~h}$ after the left intranasal administration of thallium-201 and $100 \mu \mathrm{g}$ rotenone, compared with that in control rats ( $p=0.008,5$ rats per group). Our results suggest that thallium-201 migration to the olfactory bulb is increased in intact olfactory sensory neurons with reduced pre-synaptic inhibition from dopaminergic interneurons in olfactory bulb glomeruli.
\end{abstract}

Keywords Olfactory dysfunction · Dopaminergic interneuron - Tyrosine hydroxylase · Action potential · Olfactory transport . Rotenone

Hiroshi Wakabayashi, Kohshin Washiyama and Tomohiro Noguchi contributed equally to this work.

Electronic supplementary material The online version of this article (https://doi.org/10.1007/s12035-020-02078-y) contains supplementary material, which is available to authorized users.

Hideaki Shiga

shigah@kanazawa-med.ac.jp

1 Department of Otorhinolaryngology, Kanazawa Medical University, Uchinadamachi, Kahokugun, Ishikawa 920-0293, Japan

2 Department of Nuclear Medicine, Graduate School of Medical Sciences, Kanazawa University, Kanazawa, Ishikawa 920-8640, Japan

3 Advanced Clinical Research Center, Fukushima Global Medical Science Center, Fukushima Medical University, Fukushima 960-1295, Japan

4 Department of Sensory Physiology, Asahikawa Medical University, Asahikawa 078-8510, Japan

5 Institute for Frontier Science Initiative, Kanazawa University, Kanazawa, Ishikawa 920-1192, Japan

\section{Introduction}

Detecting the mechanisms underpinning olfactory dysfunction is challenging, owing to the difficulty in directly viewing the connectivity of peripheral olfactory nerves using current magnetic resonance imaging (MRI). To date, we have visualized olfactory nerves in healthy volunteers and olfactory-impaired patients using a novel olfactory nerve tracer, radioisotope ${ }^{201} \mathrm{Tl}$ (thallium-201) [1, 2]. Thallium-201-based olfactory imaging is referred to as olfactory scintigraphy.

The radioisotope thallium-201 is transported within olfactory neural tracts after nasal administration in rodents [3]. This transport is significantly decreased by transecting olfactory nerve fibers and correlates with odor detection ability in mice $[4,5]$. Thallium can readily substitute potassium at the sodium/potassium $(\mathrm{Na}+/ \mathrm{K}+)$-membrane adenosine triphosphatase (ATPase) activation sites [6]. Furthermore, nasally administered thallium-201 may be transported into olfactory nerve cells as a substitute for potassium. 
Periglomerular cells are dopaminergic inhibitory interneurons in the glomerular layer of the olfactory bulb. The inhibitory interneurons in the olfactory bulb increase the dynamic range of information transfer from olfactory receptor neurons to olfactory bulb neurons [7] and maintain odor discriminating ability [8].

The glomerular layer of the olfactory bulb is damaged in rats treated with diethyldithiocarbamate, a toxic agent that induces the degeneration of the olfactory epithelium [9]. The olfactory bulb volume is reduced in patients with olfactory loss, which suggests that the number of dopaminergic inhibitory interneurons in the olfactory bulb of these patients is also reduced $[10,11]$. Inhibition of olfactory sensory neurons is mediated by suppression of pre-synaptic calcium influx with GABA and dopamine released from dopaminergic interneurons in olfactory bulb of the vertebrates $[12,13]$. However, it remains unclear whether thallium-201 migration to the olfactory bulb is affected by the pre-synaptic inhibition of olfactory sensory neurons from dopaminergic interneurons in olfactory bulb glomeruli of olfactory-impaired patients with a reduced olfactory bulb volume.

Rotenone, a mitochondrial respiratory chain complex I inhibitor, has been commonly used as a pesticide in agriculture [14]. In mice, nasal administration of rotenone decreases the number of dopaminergic interneurons in the olfactory bulb without decreasing the expression of olfactory marker proteins in the olfactory bulb [15].

In this study, following nasal administration of rotenone in rodents, we investigated thallium-201 migration to the olfactory bulb with a reduced number of dopaminergic interneurons in the olfactory bulb and intact olfactory sensory neurons. The aim of our study was to determine whether thallium-201 migration to the olfactory bulb is affected if the intact olfactory sensory neurons received reduced pre-synaptic inhibition signal from the dopaminergic interneurons in the olfactory bulb in vivo.

\section{Materials and Methods}

\section{Experimental Procedures}

\section{Materials}

Eight-week-old male ICR mice (CLEA Japan, Inc., Tokyo, Japan) and 8-week-old male Wistar rats (SLC Japan, Inc., Hamamatsu, Japan) were housed in a $22-26{ }^{\circ} \mathrm{C}$ airconditioned room with a 12-h light:dark cycle. Food (CLEA Japan, Inc., Tokyo, Japan) and water were provided ad libitum. Rats were selected, as opposed to mice, for in vivo imaging with SPECT-CT because the head of a mouse is too small for imaging the migration of thallium-201 to the olfactory bulb with SPECT-CT.
All animal experimental procedures were approved by the animal experiment committees of Kanazawa Medical University (Ishikawa, Japan; number: 2016-85), Kanazawa University (Ishikawa, Japan; number: AP-153663), and Asahikawa Medical University (Asahikawa, Japan; number: 17053).

\section{Nasal Administration of Thallium Chloride $\left[{ }^{201} \mathrm{Tl}\right] \mathrm{TICl}$ and Rotenone Solution in Mice}

$\left[{ }^{201} \mathrm{Tl}\right]$ Thallium (I) chloride $\left({ }^{201} \mathrm{Tl}, 74 \mathrm{MBq} / \mathrm{mL}\right)$ was administered into the left nasal cavity of each mouse via a microinjection pipette. Sneezing was prevented with anesthesia (intraperitoneal administration of a mixed solution of medetomidine $[0.75 \mu \mathrm{g} / \mathrm{g}]$, midazolam $[4 \mu \mathrm{g} / \mathrm{g}]$, and butorphanol $[5 \mu \mathrm{g} / \mathrm{g}]$ ) in phosphate-buffered saline (PBS). Mice were awakened with the intraperitoneal administration of atipamezole $30 \mathrm{~min}$ after the nasal administration of the solution. The thallium-201 solution was obtained from Nihon Medi-Physics (Tokyo, Japan). Ten microliters of thallium-201 in the vehicle control (1\% dimethyl sulfoxide [DMSO] in PBS, $N=6$ ), $10 \mu \mathrm{g}$ rotenone (Sigma, Saint Louis, MI, USA, $N=6)$, or $20 \mu \mathrm{g}$ rotenone $(N=6)$ was administered into the left nasal cavity of each normal mouse under anesthesia. Three hours after the thallium-201 nasal administration, mice were euthanized under anesthesia.

Tissue samples were obtained from the left olfactory bulb and left nasal turbinate. After the weight measurements, sample radioactivity was measured with gamma spectrometry using the Auto Well Gamma System (model ARC-380; Hitachi, Tokyo, Japan). The rate of thallium-201 migration to the olfactory bulb was calculated as the uptake of thallium-201 per gram of wet weight (\% dose/g) in the left olfactory bulb divided by the uptake of thallium-201 per gram of wet weight (\% dose/g) in the left nasal turbinate $[4,5]$.

\section{Immunohistochemistry for Dopaminergic and Olfactory Sensory Neurons}

We analyzed the expression of tyrosine hydroxylase to ascertain the location of dopaminergic interneurons in the olfactory bulb by immunohistochemical staining since tyrosine hydroxylase is a specific marker of dopaminergic interneurons [15]. The bilateral olfactory bulbs and nasal turbinates were also assessed using immunohistochemical staining for olfactory marker protein expression. Three hours after undergoing left nasal administration of $20 \mu \mathrm{g}$ rotenone in $10 \mu \mathrm{L}$ of $1 \%$ DMSO solution, normal mice $(N=6)$ were perfused with physiological saline, and fixed with $4 \%$ paraformaldehyde under anesthesia (the intraperitoneal administration of a mixed solution containing medetomidine $[0.75 \mu \mathrm{g} / \mathrm{g}]$, midazolam $[4 \mu \mathrm{g} / \mathrm{g}]$, and butorphanol $[5 \mu \mathrm{g} / \mathrm{g}])$. The head was dissected, and facial bones were removed. Following overnight fixation with $4 \%$ 
paraformaldehyde, the bilateral olfactory bulbs and nasal turbinates were resected. Sample tissues were treated in $20 \%$ sucrose solution (Sigma, Osaka, Japan) and embedded in paraffin. Samples of nasal turbinates were separated from the olfactory bulbs and were decalcified for 7 days at $4{ }^{\circ} \mathrm{C}$ with a commercially based decalcification solution (KC-X; FALMA, Tokyo, Japan) before paraffin embedding. The samples were sliced into $3-\mu \mathrm{m}$ sections and mounted on slides for immunohistochemical staining.

Sections of the bilateral olfactory bulbs were deparaffinized with xylene and rehydrated through a graded alcohol series. For the staining of tyrosine hydroxylase, after blocking and antigen retrieval $\left(90^{\circ} \mathrm{C}\right.$ for $\left.30 \mathrm{~min}\right)$, the sections were incubated with anti-tyrosine hydroxylase antibody (1:2000 dilution; Abcam, Tokyo, Japan) in an antibody diluent (Dako Cytomation, Glostrup, Denmark) for $1 \mathrm{~h}$ at $24{ }^{\circ} \mathrm{C}$. After washing with PBS, each section was incubated for $30 \mathrm{~min}$ at $24^{\circ} \mathrm{C}$ with DyLight 649conjugated anti-chicken immunoglobulin $\mathrm{G}(\mathrm{IgG})(\mathrm{H} \& \mathrm{~L})$ antibody (1:5000 dilution; Rockland, Limerick, PA, USA), and then washed in PBS. After development, the sections were mounted.

For the staining of olfactory marker protein (a marker of mature olfactory neurons), after blocking and antigen retrieval $\left(90{ }^{\circ} \mathrm{C}\right.$ for $30 \mathrm{~min}$ ), each section was incubated for $1 \mathrm{~h}$ at $24{ }^{\circ} \mathrm{C}$ with anti-olfactory marker protein antibody $(1: 100$ dilution; FUJIFILM Wako, Osaka, Japan) in an antibody diluent, and then washed in PBS. Sections were incubated for $30 \mathrm{~min}$ at room temperature with Alexa Fluor 555-conjugated anti-goat $\operatorname{IgG}(\mathrm{H} \& \mathrm{~L})$ antibody (1:200 dilution; Life Technologies, Carlsbad, CA, USA), and then washed in PBS. After developing, the sections were mounted.

The sections of nasal turbinates were also stained for olfactory marker protein. After development, the sections were lightly counterstained with 4',6-diamidino-2-phenylindole solution (DAPI) (Vector TrueVIEWTM; Vector Laboratories, CA, USA) and mounted.

For the negative control, the antibody diluent was applied instead of the primary antibody solution. Slides were observed under a fluorescence microscope (BZ-X700; Keyence Corporation, Osaka, Japan). Immunofluorescence intensity for TH and olfactory marker protein expressions in the images $(\times 40)$ was assessed with an analysis application measurement module (BZ-H3M; Keyence) in the right and left olfactory bulb of each sample. The number of olfactory marker protein-positive cells was manually counted in the $250 \mu \mathrm{m}$ basal membrane length olfactory epithelium of the middle part each side nasal septum. The histological analysis was separately performed by two investigators (HS and MK) in a blinded manner for each sample image, and the average of scores was used for statistical analysis.

\section{Electrophysiological Analysis of Olfactory Sensory Neurons}

Three hours after the intranasal administration of $20 \mu \mathrm{g}$ rotenone or the vehicle ( $1 \%$ DMSO) into the left nasal cavity, ICR male mice ( 8 weeks old) were deeply anesthetized with an intraperitoneal injection of pentobarbital sodium $(150 \mathrm{mg} / \mathrm{kg})$, followed by sevoflurane inhalation. To protect tissue from excitotoxic damage, the animals were treated with cardiac perfusion with ice-cold sucrose-based Ringer's solution (in $\mathrm{mM}$ : 234 sucrose, 2.5 potassium chloride $[\mathrm{KCl}], 26$ sodium bicarbonate $\left[\mathrm{NaHCO}_{3}\right], 1.25$ sodium dihydrogen phosphate $\left[\mathrm{NaH}_{2} \mathrm{PO}_{4}\right], 0.5$ calcium chloride $\left[\mathrm{CaCl}_{2}\right], 10$ magnesium chloride $\left[\mathrm{MgCl}_{2}\right]$, and 11 glucose, $\mathrm{pH}$ 7.4) oxygenated with 95\% oxygen $\left(\mathrm{O}_{2}\right)$ and $5 \%$ carbon dioxide $\left(\mathrm{CO}_{2}\right)$ mixed gas before decapitation.

Electrophysiology of the olfactory sensory neurons was conducted, as previously described [16]. In brief, the inside of the nasal cavity of mice was disclosed by splitting the head along the midline. A sheet of olfactory epithelium in the range between the septum and dorsal region of the nasal cavity was peeled away under a stereomicroscope. The remainder of the nasal turbinates was trimmed. The somata of olfactory sensory neurons were exposed for patch clamp recordings by making a shallow incision on the apical surface of the sensory epithelia with the tip of a 25 -gauge needle. The epithelia were incubated in normal Ringer's solution (in mM: $125 \mathrm{NaCl}, 2.5 \mathrm{KCl}, 26$ $\mathrm{NaHCO}_{3}, 1.25 \mathrm{NaH}_{2} \mathrm{PO}_{4}, 2 \mathrm{CaCl}_{2}, 1 \mathrm{MgCl}_{2}, 11$ glucose, $\mathrm{pH}$ 7.4) saturated with $\mathrm{O}_{2} / \mathrm{CO}_{2}$ gas at $37^{\circ} \mathrm{C}$ for $30 \mathrm{~min}$ and equilibrated in the same solution at room temperature (24 $26{ }^{\circ} \mathrm{C}$ ) until use.

The epithelial preparation was placed on the glass bottom of a recording chamber filled with normal Ringer's solution saturated with $\mathrm{O}_{2} / \mathrm{CO}_{2}$ gas and fixed by a U-shaped weight. Individual cells were observed by infrared differential interference contrast video microscopy through an E600FN microscope (Nikon, Tokyo, Japan) with a water-immersion 40× objective lens. Glass electrodes were filled with a potassium (K)-gluconate intracellular solution (in mM: $140 \mathrm{~K}$-gluconate, $2 \mathrm{MgCl}_{2}, 2$ adenosine triphosphate [ $\left.\mathrm{Na}_{2} \mathrm{ATP}\right], 0.5$ ethylene glycol tetra-acetic acid/potassium hydroxide [EGTA/KOH], 10 4-(2-hydroxyethyl)-1-piperazineethanesulfonic acid [HEPES], pH 7.2/KOH). The electrode resistance was $12 \pm$ $0.67 \mathrm{M} \Omega(N=32)$. The seal resistance achieved with glass electrode tips on the cell surface was $9.7 \pm 1.5 \mathrm{G} \Omega(N=28)$. Series resistance from formation of whole-cell patch configuration was $43 \pm 2.6 \mathrm{M} \Omega(N=32)$.

Membrane potential and currents were acquired using an Axopatch 200B amplifier (Molecular Devices, Sunnyvale, CA, USA) with a 10-KHz low-pass filter. They were digitized using a Digidata 1320A digitizer (Molecular Devices) controlled on pClamp software (Molecular Devices) at a sampling frequency of $20 \mathrm{kHz}$. The capacitive current and compensation of series resistance were manually subtracted by using a built-in circuit of the amplifier in the range without overcompensation. Liquid junction potentials were estimated at $15 \mathrm{mV}$ and were adjusted in the analyses. 
Single-Photon Emission Computed Tomography/Computed Tomography Analysis in Normal Rats Treated with Rotenone

Twenty-four hours after left nasal administration of $50 \mu \mathrm{L}$ of ${ }^{201} \mathrm{TlCl}$ solution with the control vehicle (1\% DMSO in PBS) or with $100 \mu \mathrm{g}$ rotenone, normal rats were examined using SPECT-CT (versatile emission computed tomography/ computed tomography; MILabs, Utrecht, Netherlands) under anesthesia. Data were acquired in list mode and dual photopeak windows (76 keV, 28\% width and $168 \mathrm{keV}, 20 \%$ width) were set after the acquisition. Triple energy window scatter correction was employed in this experiment. Data were reconstructed using pixel-based order-subsets expectation maximization in 32 subsets and 8 iterations using the method, which was previously shown [17], with correction for attenuation on computed tomography.

The obtained SPECT images were analyzed with the public domain AMIDE imaging software (version 1.01) [18]. Volumes of interest were manually placed for the olfactory nerve and nasal cavity. The ${ }^{201} \mathrm{Tl}$ migration rate to the olfactory bulb was calculated, based on the following formula: 201-Tl migration to olfactory bulb rate $(\%)=$ total counts in the olfactory bulb total counts in the nasal cavity $\times 100$. The imaging analysis was separately performed by two investigators (HW and $\mathrm{TH}$ ) in a blinded manner for each image, and the average of scores was used for statistical analysis.

\section{Statistical Analysis}

We compared mean values using a Mann-Whitney $U$ test (Prism 6, GraphPad, San Diego, CA, USA). All $p$ values were two-tailed. Electrophysiological data were analyzed with oneway ANOVA followed by Scheffe's multiple comparisons using Excel software (Microsoft, Redmond, WA, USA) with Visual Basic-based macro programs. Ward's method, a hierarchical cluster analysis, was employed for classifying olfactory sensory neurons with standardized values of conductance for voltage-gated $\mathrm{Na}^{+}\left(\mathrm{G}_{\mathrm{Na}}\right)$ and $\mathrm{K}^{+}\left(\mathrm{G}_{\mathrm{K}}\right)$ currents. In multiple comparisons for proportion tests, $\alpha$-error rate was corrected with Ryan's nominal significance level. Data values are shown as mean $\pm 95 \%$ confidence intervals unless otherwise noted. A $p$ value of $<0.05$ was considered statistically significant.

\section{Results}

\section{Nasal Administration of ${ }^{201} \mathrm{TICl}$ and Rotenone Solution in Mice}

Three hours after intranasal administration of ${ }^{201} \mathrm{Tl}$ and rotenone, the thallium-201 migration rate to the olfactory bulb was significantly increased in normal mice (Mann-Whitney test: $10 \mu \mathrm{g}$ rotenone, $p=0.0012$, the mean \pm the S.D. $=39.8$ $\pm 6.1, N=6 ; 20 \mu \mathrm{g}$ rotenone, $p=0.0012$, the mean \pm the S.D. $=50.1 \pm 9.1, N=6$; Fig. 1), compared with the rate after treatment with ${ }^{201} \mathrm{Tl}$ and the vehicle control (1\% DMSO in PBS, the mean \pm the S.D. $=23.5 \pm 7.2, N=6)$. We selected $20 \mu \mathrm{g}$ rotenone as the treatment in subsequent experiments.

\section{Immunohistochemistry for Dopaminergic and Olfactory Sensory Neurons}

The ratio of tyrosine hydroxylase expression divided by the olfactory marker protein expression in the left olfactory bulb was significantly decreased $3 \mathrm{~h}$ after the left intranasal administration of $20 \mu \mathrm{g}$ rotenone, compared with the ratio in the right olfactory bulb in the mice (Mann-Whitney test, $p=$ 0.0002 , 6 mice per group; Fig. 2a). Representative axial images of tyrosine hydroxylase and olfactory marker protein expressions, determined using immunohistochemical staining in the olfactory bulb of mice treated with $20 \mu \mathrm{g}$ rotenone, are in Fig. 2b. Tyrosine hydroxylase expressions were observed predominantly in the glomerular layer of the olfactory bulb.

The number of cells positive with olfactory marker protein expression in the left olfactory epithelium was not significantly changed $3 \mathrm{~h}$ following left intranasal administration of $20 \mu \mathrm{g}$ rotenone, compared with those in the right olfactory epithelium in the mice. The number of cells positive with olfactory marker protein expression per $250 \mu \mathrm{m}$ of basal layer length in the middle part of each bilateral nasal septal olfactory epithelium was as follows (presented as the mean \pm the S.D.): right side, $111.2 \pm 26.5$; left side, $110.2 \pm 24.9$ (MannWhitney test, $p=0.73,6$ animals per group). Representative

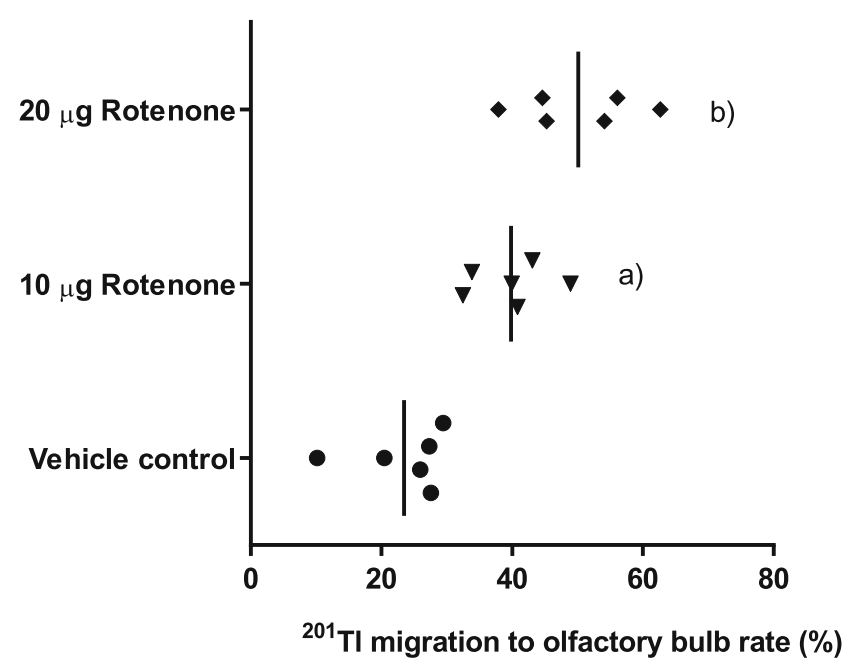

Fig. 1 The thallium-201 migration rate to the olfactory bulb was significantly increased in normal mice $3 \mathrm{~h}$ after the left intranasal administration of ${ }^{201} \mathrm{Tl}$ and rotenone ([a] $10 \mu \mathrm{g}$ rotenone, $p=0.0012, N=6$; [b] $20 \mu \mathrm{g}$ rotenone, $p=0.0012, N=6$ ) compared with the rate after treatment with ${ }^{201} \mathrm{Tl}$ and the vehicle control (1\% DMSO in PBS, $N=6$ ). The bars indicate the mean 
Fig. 2 (a) The ratio of tyrosine hydroxylase (TH) expression divided by the olfactory marker protein (OMP) expressions in the left olfactory bulb was significantly decreased $3 \mathrm{~h}$ after the left intranasal administration of $20 \mu \mathrm{g}$ rotenone, compared with the ratio in the right olfactory bulb in the mice ([a] $p=0.0002, N=6$ / group). The bars indicate mean. (b) Representative axial images of TH (green) and OMP (magenta) expressions determined with immunohistochemical staining in the olfactory bulb of mice treated with $20 \mu$ g rotenone. $\mathrm{R}$, right side; $\mathrm{L}$, left side. TH expression was mostly observed in the glomerular layer of the olfactory bulb. The bars indicate $500 \mu \mathrm{m}$. (c) Representative images of olfactory marker protein (OMP; red) and DAPI (blue) expression determined with immunohistochemical staining in the olfactory epithelium of mice $3 \mathrm{~h}$ after the left intranasal administration of $20 \mu \mathrm{g}$ rotenone. Scale bars indicate $100 \mu \mathrm{m}$. Rt, right; Lt, left (a)

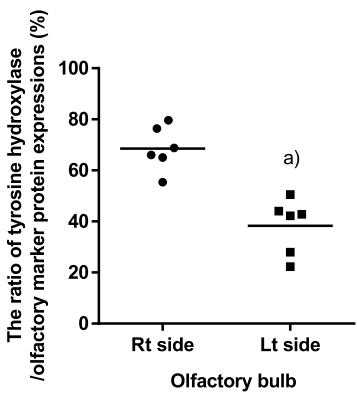

(b)
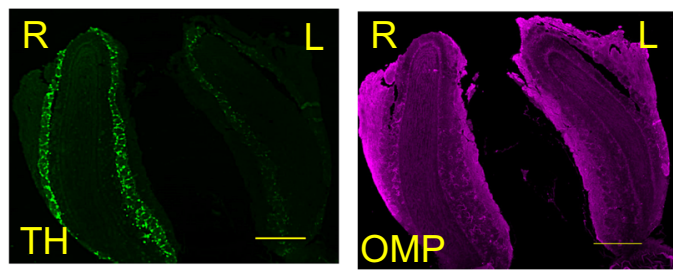

(c)

Olfactory epithelium

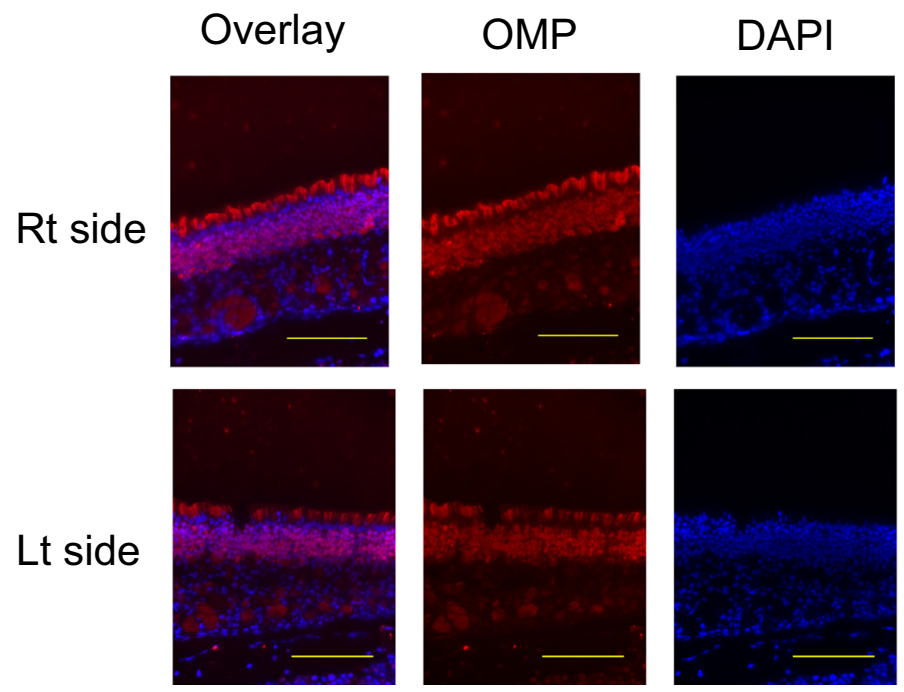

images of olfactory marker protein expression, determined using immunohistochemical staining in the olfactory epithelium of mice treated with $20 \mu \mathrm{g}$ rotenone, are shown in Fig. 2c.

\section{Electrophysiological Analysis of Olfactory Sensory Neurons}

Electrophysiological recordings were performed in normal Ringer's solution containing no rotenone. Firing properties were compared between olfactory sensory neurons in the right olfactory epithelium isolated from vehicle control mice $\left(\mathrm{Co}_{\mathrm{Rt}}\right)$, left epithelium from the control $\left(\mathrm{Co}_{\mathrm{Lt}}\right)$, right epithelium from rotenone administration mice $\left(\mathrm{Ro}_{\mathrm{Rt}}\right)$, and left epithelium from the rotenone mice $\left(\mathrm{Ro}_{\mathrm{Lt}}\right)$. Vehicle $(1 \% \mathrm{DMSO})$ or $20 \mu \mathrm{g}$ rotenone was administered to the left nasal cavity of mice as described in the material and methods section.

First, olfactory sensory neurons generated action potentials in response to 10-pA current step pulses for $100 \mathrm{~ms}$ although the $\mathrm{Ro}_{\mathrm{Lt}}$ cells ceased firing spontaneously despite the continuous current injection (Fig. 3a). Increases in numbers of action potentials with increasing current injection were suppressed in the $\mathrm{Ro}_{\mathrm{Lt}}$ cells (Fig. $3 \mathrm{~b}$ ). The number of action potentials elicited in the $\mathrm{Ro}_{\mathrm{Lt}}$ cells by $10-\mathrm{pA}$ current stimulus was significantly reduced ( $p=0.0147,0.0029$, and $1.9 \times 10^{-4}$; Scheffe's multiple comparison) compared with $\mathrm{Co}_{\mathrm{Rt}}, \mathrm{Co}_{\mathrm{Lt}}$, and $\mathrm{Ro}_{\mathrm{R}}$, respectively (Fig. $3 \mathrm{c}$ ). Shapes of single action potentials produced by the $\mathrm{Ro}_{\mathrm{Lt}}$ cells were higher and broader than that by the other cells (Fig. 3d). Furthermore, rising and decaying slopes in the action potentials decreased in the $\mathrm{Ro}_{\mathrm{Lt}}$ cells (Fig. 3e). The characteristics of the action potentials of the $\mathrm{Ro}_{\mathrm{Lt}}$ cells imply delay of repolarization due to decrease in voltage-gated currents. Mean values of membrane capacitance $\left(\mathrm{C}_{\mathrm{m}}\right)$, membrane resistance $\left(\mathrm{R}_{\mathrm{m}}\right)$, and conductance of voltagegated $\mathrm{Na}^{+}\left(\mathrm{G}_{\mathrm{Na}}\right)$ and $\mathrm{K}^{+}\left(\mathrm{G}_{\mathrm{K}}\right)$ currents were compared between $\mathrm{Co}_{\mathrm{Rt}}, \mathrm{Co}_{\mathrm{Lt}}, \mathrm{Ro}_{\mathrm{Rt}}$, and $\mathrm{Ro}_{\mathrm{Lt}}$ (Fig. 3f). No statistical significance $(p>0.05)$ was shown by one-way ANOVA in all comparisons.

Subsequently, olfactory sensory neurons were classified based on the values of $\mathrm{G}_{\mathrm{Na}}$ and $\mathrm{G}_{\mathrm{K}}$ by using cluster analysis and were divided into two groups of large conductance (LG) and small conductance (SG) cells (Fig. 4a). LG cells showing larger $\mathrm{G}_{\mathrm{Na}}$ consist of $5 \mathrm{Co}_{\mathrm{Rt}}$ cells, $4 \mathrm{Co}_{\mathrm{Lt}}$ cells, $7 \mathrm{Ro}_{\mathrm{Rt}}$ cells, 
(a)

Vehicle control (Co)

Right (Rt) Left (Lt)
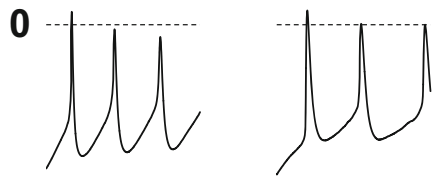

(b)

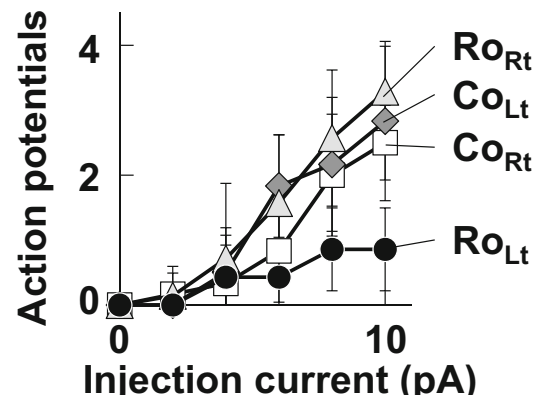

(d)

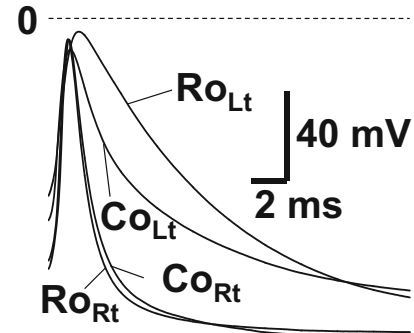

(f)

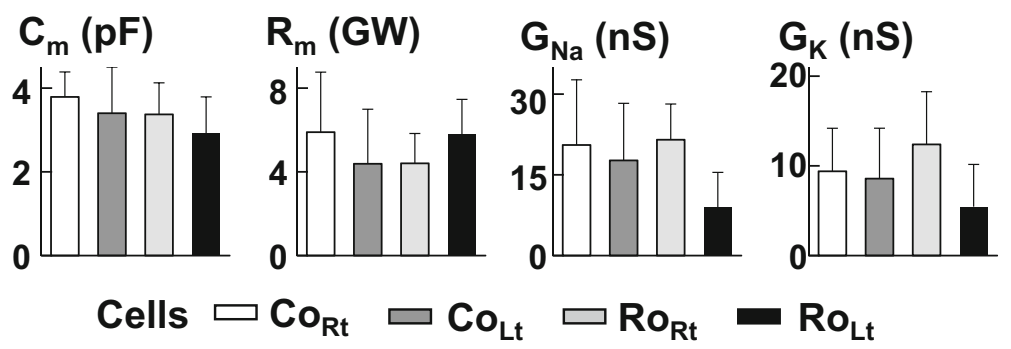

$20 \mu \mathrm{g}$ Rotenone (Ro)

Right (Rt) Left (Lt)

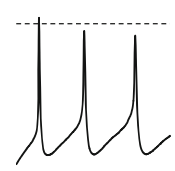

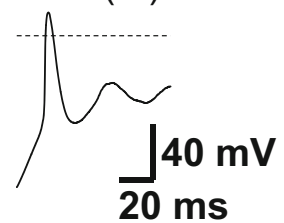

(c)

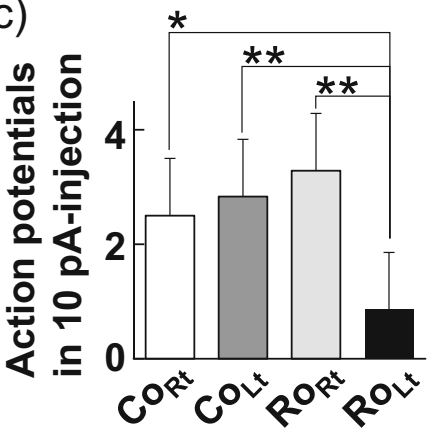

Fig. 3 Excitability of olfactory sensory neurons $3 \mathrm{~h}$ after the left intranasal administration of $20 \mu \mathrm{g}$ rotenone or the vehicle control $(1 \%$ DMSO) in normal mice. (a) Typical firing of olfactory sensory neurons after intranasal administration of $20 \mu \mathrm{g}$ rotenone or vehicle control. Action potentials were elicited by $10-\mathrm{pA}$ current injections. (b) Relationships between number of action potentials and amplitude of injection currents during 100-ms step pulses. Squares and diamonds: olfactory sensory neurons on the right and left olfactory epithelium in the control mice (CoRt, $N=6$ and CoLt, $N=6$ ), respectively; triangles and circles: olfactory sensory neurons on the right and left olfactory epithelium in $20 \mu \mathrm{g}$ rotenone-treated mice (RoRt, $N=7$ and RoLt, $N=7$ ), respectively. (c) Significant reduction of the number of action potentials by the intranasal administration of rotenone. Data points are shown in Fig. 3b

and $1 \mathrm{Ro}_{\mathrm{Lt}}$ cell (total of 17 cells) and SG cells showing smaller $\mathrm{G}_{\mathrm{Na}}$ consist of $2 \mathrm{Co}_{\mathrm{Rt}}$ cells, $4 \mathrm{Co}_{\mathrm{Lt}}$ cells, $2 \mathrm{Ro}_{\mathrm{Rt}}$ cells, and 7

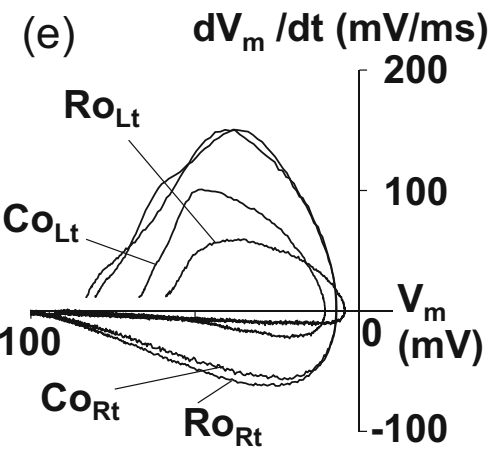

at 10 pA. $* * p<0.01$ and $* p<0.05$ by Scheffe's multiple comparisons following one-way ANOVA. (d) Different form of action potentials in ensemble average: $\operatorname{CoRt}(N=3), \operatorname{CoLt}(N=6), \operatorname{RoRt}(N=6), \operatorname{RoLt}(N=$ 4). (e) Phase-plane plot for the action potentials shown in Fig. $3 \mathrm{~d}$. The ensemble average of the time derivative of the action potential $(\mathrm{dVm} / \mathrm{dt})$ is plotted to the average value of $\mathrm{Vm}$ of each time point. The time derivative of the membrane potentials shows current density through voltagegated channels (Iionic/Cm $=-\mathrm{dVm} / \mathrm{dt}$ ). (f) Comparison of membrane properties between CoRt $(N=7), \operatorname{CoLt}(N=8)$, RoRt $(N=9)$, and RoLt $(N=8)$. Cm, membrane capacitance; Rm, membrane resistance; $\mathrm{GNa}$ and GK, conductance for voltage-gated $\mathrm{Na}+$ and $\mathrm{K}+$ currents, respectively. No statistical significance was shown by one-way ANOVA in all comparison

$\mathrm{Ro}_{\mathrm{Lt}}$ cells (total of 15 cells) (Fig. 4b). The mean value of $\mathrm{G}_{\mathrm{Na}}$ in LG cells $(26 \pm 3.3 \mathrm{nS})$ is significantly larger $(p=1.1 \times$ 
Fig. 4 Clustering of olfactory sensory neurons $3 \mathrm{~h}$ after the left intranasal administration of $20 \mu \mathrm{g}$ rotenone or the vehicle control (1\% DMSO) in normal mice. (a) Dendrogram showing olfactory sensory neurons clustered based on the values of GNa and GK. Examined cells comprising of $\operatorname{CoRt}(N=7), \operatorname{CoLt}(N=8), \operatorname{RoRt}$ $(N=9)$, and $\operatorname{RoLt}(N=8)$ were divided into large conductance (LG) cells of 17 and small conductance (SG) cells of 15. (b) Distribution of LG and SG cells on the GNa-GK plane. Dashed line indicates a statistically significant boundary between LG and SG, estimated by linear discriminant analysis (Wilk's $\Lambda$, $\left.0.25 ; p=1.4 \times 10^{-9}\right)$. Squares: CoRt; diamonds: CoLt; triangles: RoRt; circles: RoLt. (c)

Comparisons of means for $\mathrm{GNa}$ (left) and GK (right) between LG and SG. $* * p<0.01 ; * p<0.05$ Welch's $t$ test. (d) Significant difference in proportion of olfactory sensory neurons between LG and SG (Fisher's exact test, $p=$ 0.042). (e) Comparing proportion of olfactory sensory neurons classified into LG and SG between CoRt, CoLt, RoRt, and RoLt. * $p<$ Ryan's nominal significance level. The significance level of $\alpha$ is set at 0.05 on the whole (a)

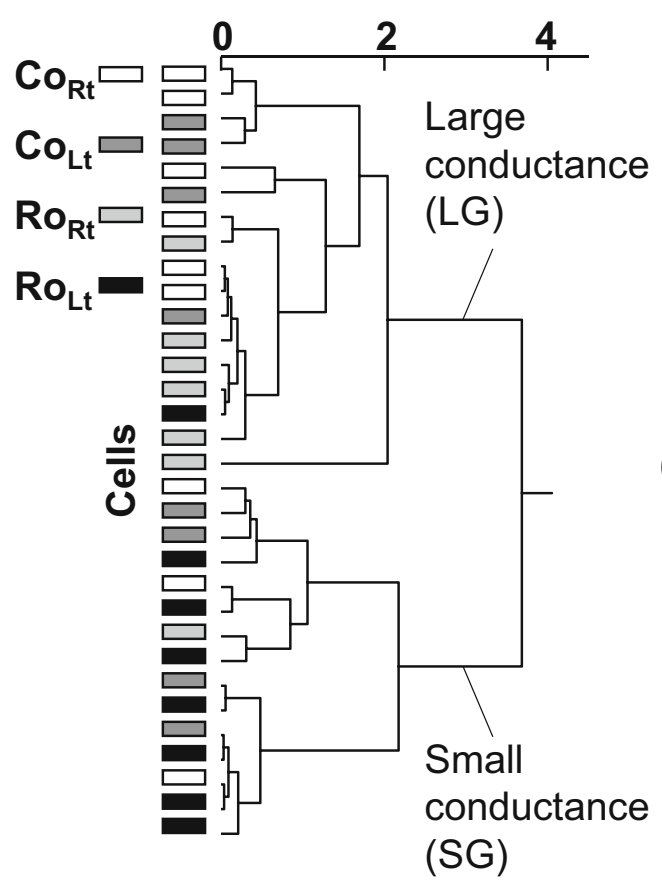

(b)

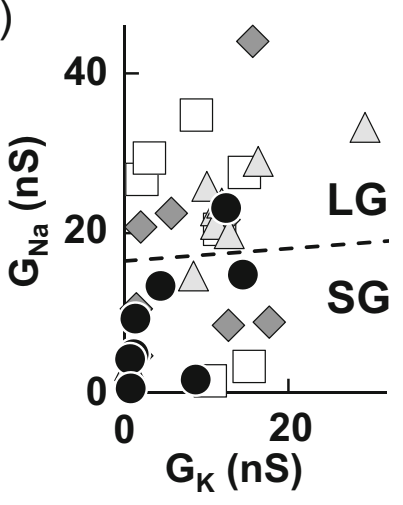

(c)

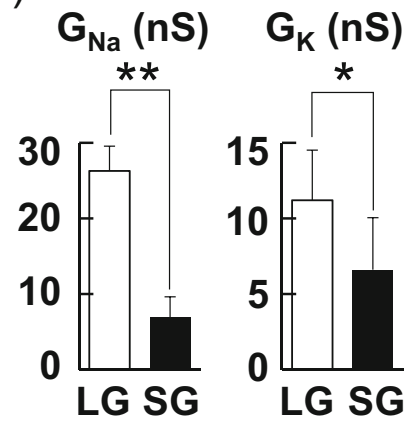

(d)

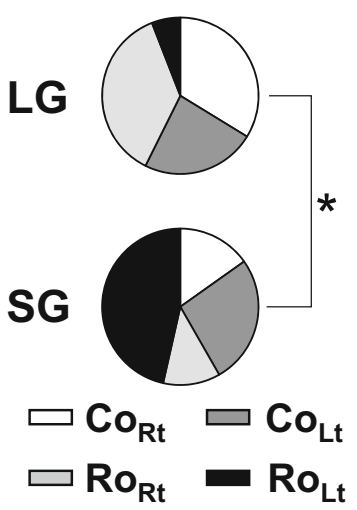

(e)

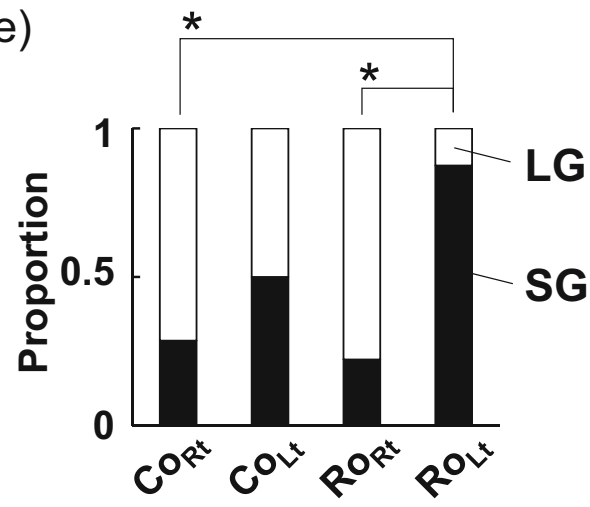

$10^{-10}$, Welch's $t$ test) than that in SG cells $(6.9 \pm 2.7 \mathrm{nS})$. In addition, $\mathrm{G}_{\mathrm{K}}$ of $\mathrm{LG}$ cells $(11 \pm 3.3 \mathrm{nS})$ is significantly larger $(p=0.049$, Welch's $t$ test $)$ than that of SG cells $(6.6 \pm 3.4 \mathrm{nS})$ (Fig. $4 \mathrm{c}) . \mathrm{C}_{\mathrm{m}}$ showed a significant difference $(p=0.042$, Welch's $t$ test) between LG cells $(3.7 \pm 0.56 \mathrm{pF})$ and SG cells $(3.0 \pm 0.46 \mathrm{pF})$ but $\mathrm{R}_{\mathrm{m}}$ showed no significant difference $(p=$ 0.80 , Welch's $t$ test) between LG cells $(5.2 \pm 1.3 \mathrm{G} \Omega)$ and SG cells $(5.0 \pm 1.4 \mathrm{G} \Omega)$.

Proportion of cells composing each group is significantly different ( $p=0.042$, Fisher's exact test) between LG and SG cells (Fig. 4d). Particularly, proportion of $\mathrm{Ro}_{\mathrm{Lt}}$ cells classified into SG cells (7 of 8 cells, $88 \%)$ is significantly larger $(p=$ 0.011 and $p=3.6 \times 10-3$, Ryan's multiple comparison) than that of $\mathrm{Co}_{\mathrm{Rt}}\left(2\right.$ of 7 cells, $29 \%$ ) and $\mathrm{Ro}_{\mathrm{Rt}}$ ( 2 of 9 cells, $22 \%$ ) cells, respectively (Fig. 4e). These results suggest that the rotenone administration to nasal cavity increases occurrence ratio of smaller $\mathrm{G}_{\mathrm{Na}}$ and $\mathrm{G}_{\mathrm{K}}$ in olfactory sensory neurons on the drug administered side.

\section{SPECT-CT Analysis in Normal Rats Treated with Rotenone}

We assessed SPECT-CT images obtained $24 \mathrm{~h}$ following nasal administration of ${ }^{201} \mathrm{Tl}$ in the rats. The thallium-201 migration rate to the olfactory bulb, as assessed with SPECT-CT, was significantly increased in normal rats $24 \mathrm{~h}$ following intranasal administration of ${ }^{201} \mathrm{Tl}$ and $100 \mu \mathrm{g}$ rotenone, compared with the rate following treatment with ${ }^{201} \mathrm{Tl}$ and vehicle control (1\% DMSO in PBS) (Fig. 5a, Mann-Whitney test, $p=$ $0.008,5$ rats per group). An increase in the thallium-201 migration rate to the olfactory bulb in rats treated with $100 \mu \mathrm{g}$ 
Fig. 5 (a) The thallium-201 migration rate to the olfactory bulb assessed with SPECT-CT was significantly increased in normal rats $24 \mathrm{~h}$ after the left intranasal administration of ${ }^{201} \mathrm{Tl}$ and $100 \mu \mathrm{g}$ rotenone, compared with the rate after treatment with ${ }^{201} \mathrm{Tl}$ and the vehicle control $(1 \%$ DMSO in PBS) ((a) $p=0.008$, $N=5$ /group). The bars indicate the mean. (b) Representative axial images of SPECT-CT $24 \mathrm{~h}$ after nasal administration of ${ }^{201} \mathrm{Tl}$ with vehicle control (a) or $100 \mu \mathrm{g}$ rotenone (b). $\mathrm{R}$, right side; $\mathrm{L}$, left side
(A)

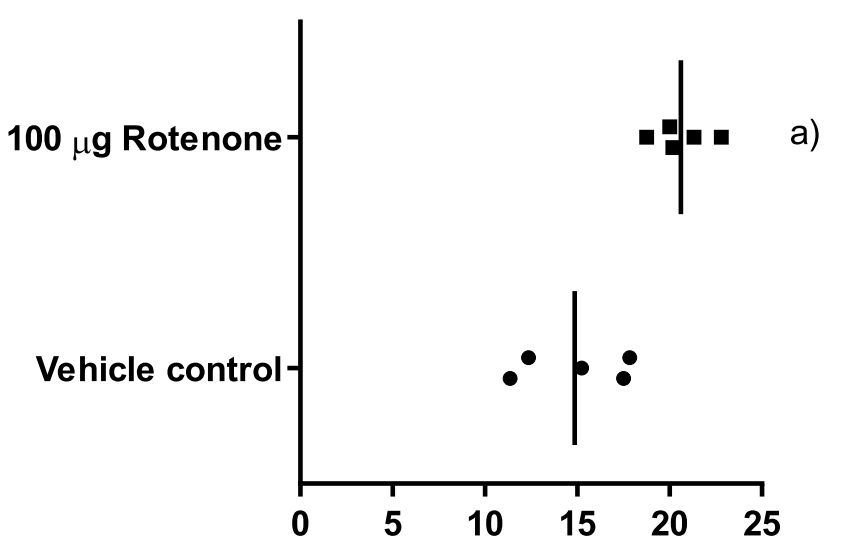

${ }^{201} \mathrm{TI}$ migration to olfactory bulb rate (\%)

(B)

Vehicle control

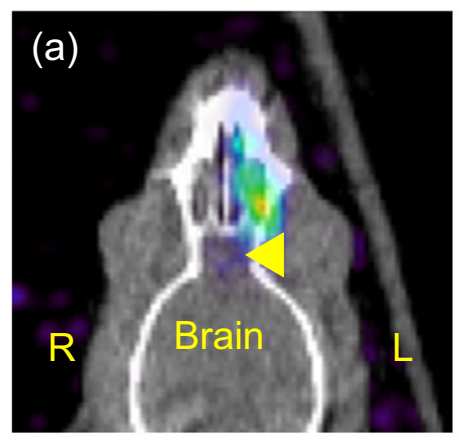

$100 \mu \mathrm{g}$ Rotenone

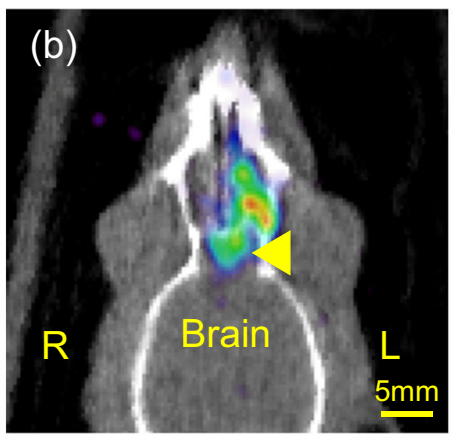

Low rotenone, compared with the rate in the control rats, was detected with in vivo imaging (Fig. 5b).

\section{Discussion}

In this study, we aimed to determine whether thallium-201 migration to the olfactory bulb is affected by pre-synaptic inhibition of olfactory sensory neurons from the dopaminergic interneurons in the olfactory bulb in vivo. To accomplish this, we investigated thallium-201 migration to the olfactory bulb in mice with reduced numbers of dopaminergic interneurons in the olfactory bulb and mature olfactory sensory neurons without significant damage, after the nasal administration of rotenone.

The thallium-201 migration rate to the olfactory bulb was significantly increased after the intranasal administration of ${ }^{201} \mathrm{Tl}$ and rotenone in mice. Dopaminergic neurons exhibit high sensitivity to rotenone-induced cytotoxicity mediated by reactive oxygen species $[14,15]$. In the current study, tyrosine hydroxylase expression, which is a specific marker of

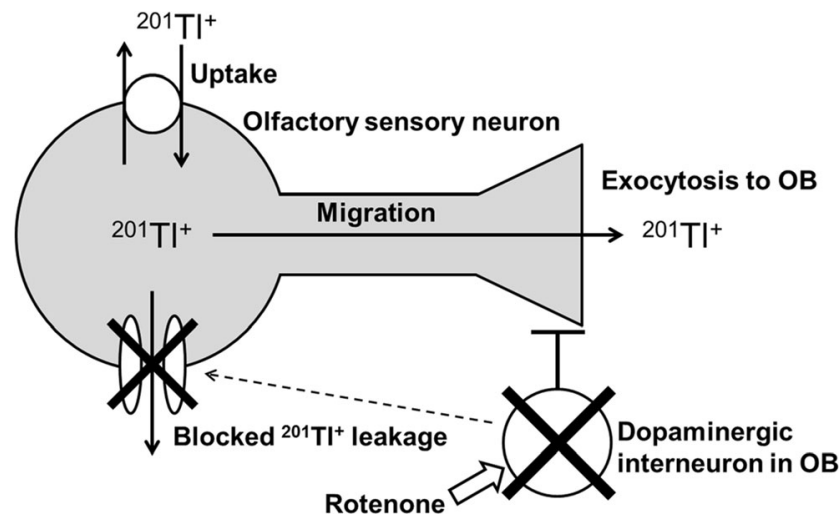

Fig. 6 Mechanisms by which intranasal administration of rotenone induces persistent changes in intrinsic excitability of olfactory sensory neurons. In this study, because rotenone administrated to the nasal cavity was washed out in the dissection of olfactory epithelium before electrophysiological recordings, such long-lasting inhibition of ion channels by rotenone may be related with plasticity of neuronal excitability. The membrane resistance showed no degradation with the rotenone administration, indicating that the cell membrane has an insignificant damage. The intact membrane retains ${ }^{201} \mathrm{Tl}^{+}$that $\mathrm{Na}^{+} / \mathrm{K}^{+}$-ATPase takes into the intracellular space. Therefore, ${ }^{201} \mathrm{Tl}^{+}$spreads more toward the axon terminals of olfactory sensory neurons when administrated together with rotenone. $\mathrm{OB}$, olfactory bulb 
dopaminergic interneurons in the glomerular layer of the olfactory bulb, was significantly decreased after intranasal administration of rotenone in mice. Periglomerular cells are dopaminergic inhibitory interneurons in the olfactory bulb. The decrease in tyrosine hydroxylase expression in the glomerular layer of the olfactory bulb after the intranasal administration of rotenone suggested that the numbers of periglomerular cells were reduced in mice treated with rotenone.

In this study, mice olfactory neurons were not significantly damaged $3 \mathrm{~h}$ following $20 \mu \mathrm{g}$ rotenone treatment, thereby promoting nasal thallium-201 migration to the olfactory bulb, while nasal thallium-201 migration to the olfactory bulb is reduced in patients with impaired olfaction due to upper respiratory tract infections, compared with ${ }^{201} \mathrm{Tl}$ migration in healthy volunteers [2]. Histopathological analyses have shown damage to the olfactory epithelium in patients with impaired olfaction due to upper respiratory tract infection [19]. Decreased olfactory bulb volume has been reported in patients with impaired olfaction caused by upper respiratory tract infections [2]. Therefore, a disconnection between the olfactory epithelium and glomeruli in the olfactory bulb may occur in patients with impaired olfaction due to upper respiratory tract infections since intact connectivity of olfactory sensory neurons implies enhanced nasal thallium-201 migration to the olfactory bulb in these patients. Decrease in both thallium201 migration rate to the olfactory bulb and olfactory bulb volume are shown in patients with parosmia and normal odor recognition thresholds after upper respiratory tract infection [20]. Incomplete regeneration of olfactory sensory neurons may cause disconnection between the olfactory epithelium and glomeruli in the olfactory bulb in these patients with parosmia.

Three hours following intranasal administration of rotenone, numbers of action potentials decreased in olfactory sensory neurons only on the rotenone treated side. The reduction of firing rate may suppress leakage of intracellular ${ }^{201} \mathrm{Tl}^{+}$via voltage-gated $\mathrm{K}^{+}$channels during repolarization following action potentials, because voltage-gated $\mathrm{K}^{+}$channels are highly permeable to thallium [21]. In addition, membrane resistance showed no degradation with the rotenone administration, indicating that the cell membrane undergoes insignificant damage. Intact membrane retains thallium-201 that the $\mathrm{Na}^{+} / \mathrm{K}^{+}$ATPase takes into intracellular space. Therefore, ${ }^{201} \mathrm{Tl}^{+}$ spreads more toward the axon terminals of olfactory sensory neurons when administrated together with rotenone (Fig. 6).

Mechanisms by which intranasal administration of rotenone induced persistent changes in intrinsic excitability of olfactory sensory neurons remain unclear. One possible mechanism is the acute action of rotenone that involves modulation of ion channels through the production of reactive oxygen species [22]. However, in this study, because rotenone administrated to the nasal cavity was washed out in dissection of olfactory epithelium before electrophysiological recordings, such long-lasting inhibition of ion channels by rotenone may be related with plasticity of neuronal excitability (Fig. 6).
With the use of in vivo imaging via SPECT-CT, we demonstrated that thallium-201 migration to the axon terminals of olfactory sensory neurons was increased under reduced inhibitory input from damaged olfactory bulb interneurons, following nasal administration of rotenone in rats. Decreased thallium-201 migration rate to the olfactory bulb predicted a poorer prognosis for patients with idiopathic olfactory dysfunction [23]. Patients with idiopathic olfactory dysfunction and decreased thallium-201 migration rate to the olfactory bulb may be at high risk for pre-symptomatic idiopathic Parkinson's disease because the overexpression of dopaminergic interneurons in the olfactory bulbs of patients diagnosed with idiopathic Parkinson's disease has been demonstrated [24].

A limitation of this study is that we did not assess changes in thallium-201 migration rate to the olfactory bulb in mice with overexpressed olfactory bulb dopaminergic interneurons. In a current ongoing clinical trial, a thallium-201-based olfactory nerve imaging method, called olfactory scintigraphy, is under investigation with the aim of determining the thallium201 migration rate to the olfactory bulb in idiopathic Parkinson's disease. Chronic subcutaneous administration of rotenone induces the pathology of Parkinson's disease in rats [25]. Therefore, farmers who experienced nasal rotenone intake during their early life may be at high risk for developing a neurological disorder similar to Parkinson's disease. Olfactory scintigraphy that could be used to detect enhanced olfactory transport of thallium-201 could potentially allow clinicians to begin treatment sooner and prevent or lessen symptoms of a neurological disorder similar to Parkinson's disease.

In conclusion, we demonstrated increased nasal thallium201 migration to the olfactory bulb in mice with damage to dopaminergic interneurons in the olfactory bulb without significant damage to olfactory sensory neurons. Our findings suggested that thallium-201 migration to the axon terminals of olfactory sensory neurons was increased owing to delayed repolarization under reduced inhibitory input from damaged olfactory bulb interneurons after the nasal administration of rotenone. The thallium-201-based olfactory imaging may be useful for the diagnosis of subjects who are at risk for developing a neurological disorder similar to Parkinson's disease. A disconnection between the olfactory epithelium and glomeruli in the olfactory bulb may occur in patients with impaired olfaction, reduced olfactory bulb volume, and nasal thallium-201 migration to the olfactory bulb, since intact connectivity of olfactory sensory neurons implies enhanced nasal thallium-201 migration to the olfactory bulb in these patients.

Acknowledgments We would like to express our sincere gratitude to the late Professor Makoto Kashiwayanagi, who passed away on July 17, 2019 , for his great guidance in the electrophysiological analysis. We also thank Mr. Ninomiya for the technical support in immunohistochemical staining. 
Authors' Contributions All authors had full access to all the data in this study and take responsibility for the integrity of the data and accuracy of data analysis. HS and KW created the study concept and design and directed the animal studies. HS, HW, TN, SM, KO, and TM participated in the drafting and editing of the manuscript. HS, HW, and TN conducted the statistical analysis. HS and MK contributed to the immunohistochemical staining analysis. TN, SM, and MK contributed to the electrophysiological analysis. HW, TH, JT, and SK contributed to the SPECT-CT imaging analysis. All authors have read and approved the final manuscript.

Funding Information This work was supported, in part, by the Japan Society for the Promotion of Science KAKENHI, Tokyo, Japan (grant number JP17K11369), which was awarded to HS.

\section{Compliance with Ethical Standards}

All procedures used in this study were in accordance with the ethical standards of the institutional animal experiment committees. The studies involving animal experiments were conducted in accordance with the 1996 revised National Institute of Health (NIH) Guide for the Care and Use of Laboratory Animals (NIH, Bethesda, MD, USA; publication no. 80-23). This article does not contain any studies with subjects conducted by any of the authors.

Conflict of Interest The authors declare that they have no conflict of interest.

Open Access This article is licensed under a Creative Commons Attribution 4.0 International License, which permits use, sharing, adaptation, distribution and reproduction in any medium or format, as long as you give appropriate credit to the original author(s) and the source, provide a link to the Creative Commons licence, and indicate if changes were made. The images or other third party material in this article are included in the article's Creative Commons licence, unless indicated otherwise in a credit line to the material. If material is not included in the article's Creative Commons licence and your intended use is not permitted by statutory regulation or exceeds the permitted use, you will need to obtain permission directly from the copyright holder. To view a copy of this licence, visit http://creativecommons.org/licenses/by/4.0/.

\section{References}

1. Shiga H, Taki J, Yamada M, Washiyama K, Amano R, Matsuura Y, Matsui O, Tatsutomi S et al (2011) Evaluation of the olfactory nerve transport function by SPECT-MRI fusion image with nasal thallium-201 administration. Mol Imaging Biol 13:1262-1266. https://doi.org/10.1007/s11307-010-0461-3

2. Shiga H, Taki J, Washiyama K, Yamamoto J, Kinase S, Okuda K, Kinuya S, Watanabe N et al (2013) Assessment of olfactory nerve by SPECT-MRI image with nasal thallium-201 administration in patients with olfactory impairments in comparison to healthy volunteers. PLoS One 8:e57671. https://doi.org/10.1371/journal.pone. 0057671

3. Kanayama Y, Enomoto S, Irie T, Amano R (2005) Axonal transport of rubidium and thallium in the olfactory nerve of mice. Nucl Med Biol 32:505-512. https://doi.org/10.1016/j.nucmedbio.2005.03. 009

4. Kinoshita Y, Shiga H, Washiyama K, Ogawa D, Amano R, Ito M, Tsukatani T, Furukawa M et al (2008) Thallium transport and the evaluation of olfactory nerve connectivity between the nasal cavity and olfactory bulb. Chem Senses 33:73-78. https://doi.org/10. 1093/chemse/bjm066

5. Shiga H, Kinoshita Y, Washiyama K, Ogawa D, Amano R, Hirota K, Tsukatani T, Furukawa M et al (2008) Odor detection ability and thallium-201 transport in the olfactory nerve of traumatic olfactoryimpaired mice. Chem Senses 33:633-637. https://doi.org/10.1093/ chemse/bjn030

6. Ando A, Ando I, Katayama M, Sanada S, Hiraki T, Mori H, Tonami N, Hisada K (1988) Biodistributions of radioactive alkaline metals in tumor bearing animals: comparison with 201Tl. Eur J Nucl Med 14:352-357. https://doi.org/10.1007/BF00254383

7. Ennis M, Zhou FM, Ciombor KJ, Aroniadou-Anderjaska V, Hayar A, Borrelli E, Zimmer LA, Margolis F et al (2001) Dopamine D2 receptor-mediated presynaptic inhibition of olfactory nerve terminals. J Neurophysiol 86:2986-2997. https://doi.org/10.1152/jn. 2001.86.6.2986

8. Tillerson JL, Caudle WM, Parent JM, Gong C, Schallert T, Miller GW (2006) Olfactory discrimination deficits in mice lacking the dopamine transporter or the D2 dopamine receptor. Behav Brain Res 172:97-105. https://doi.org/10.1016/j.bbr.2006.04.025

9. Struble RG, Beckman SL, Fesser E, Nathan BP (2001) Volumetric and horseradish peroxidase tracing analysis of rat olfactory bulb following reversible olfactory nerve lesions. Chem Senses 26: 971-981. https://doi.org/10.1093/chemse/26.8.971

10. Rombaux P, Mouraux A, Bertrand B, Nicolas G, Duprez T, Hummel T (2006) Olfactory function and olfactory bulb volume in patients with postinfectious olfactory loss. Laryngoscope 116: 436-439. https://doi.org/10.1097/01.MLG.0000195291.36641.1E

11. Huart C, Rombaux P, Hummel T (2013) Plasticity of the human olfactory system: the olfactory bulb. Molecules 18:11586-11600. https://doi.org/10.3390/molecules180911586

12. Wachowiak M, Cohen LB (1999) Presynaptic inhibition of primary olfactory afferents mediated by different mechanisms in lobster and turtle. J Neurosci 19:8808-8817. https://doi.org/10.1523/ JNEUROSCI.19-20-08808

13. Maher BJ, Westbrook GL (2008) Co-transmission of dopamine and GABA in periglomerular cells. J Neurophysiol 99:1559-1564. https://doi.org/10.1152/jn.00636.2007

14. Bisbal M, Sanchez M (2019) Neurotoxicity of the pesticide rotenone on neuronal polarization: a mechanistic approach. Neural Regen Res 14:762-766. https://doi.org/10.4103/1673-5374. 249847

15. Sasajima H, Miyazono S, Noguchi T, Kashiwayanagi M (2015) Intranasal administration of rotenone in mice attenuated olfactory functions through the lesion of dopaminergic neurons in the olfactory bulb. Neurotoxicology 51:106-115. https://doi.org/10.1016/j. neuro.2015.10.006

16. Noguchi T, Miyazono S, Kashiwayanagi M (2019) Stimulus dynamics-dependent information transfer of olfactory and vomeronasal sensory neurons in mice. Neuroscience 400:68-61. https://doi.org/10.1016/j.neuroscience.2018.12.043

17. Shibutani T, Onoguchi M, Kanno T, Mochizuki T, Shiba K, Kinuya S (2018) Relationship between radioactivity concentration ratio and cross-talk correction effect for simultaneous $99 \mathrm{mTc}$ and $18 \mathrm{~F}$ acquisition using small-animal SPECT-PET/CT system. J Nucl Med 59(Suppl. 1):1824 http://jnm.snmjournals.org/content/59/ supplement_1/1824. Accessed 1 May 2018

18. Loening AM, Gambhir SS (2003) AMIDE: a free software tool for multimodality medical image analysis. Mol Imaging 2:131-137. https://doi.org/10.1162/15353500200303133

19. Moran DT, Jafek BW, Eller PM, Rowelly JC 3rd (1992) Ultrastructural histopathology of human olfactory dysfunction. Microsc Res Tech 23:103-110. https://doi.org/10.1002/jemt. 1070230202

20. Shiga H, Okuda K, Taki J, Watanabe N, Tonami H, Kinuya S, Miwa T (2019) Nasal thallium-201 uptake in patients with 
parosmia with and without hyposmia after upper respiratory tract infection. Int Forum Allergy Rhinol 9:1252-1256. https://doi.org/ 10.1002/alr.22395

21. Hille B (1973) Potassium channels in myelinated nerve selective permeability to small cations. J Gen Physiol 61:669-686. https:// doi.org/10.1085/jgp.61.6.669

22. Huang CW, Lin KM, Hung TY, Chuang YC, Wu SN (2018) Multiple actions of rotenone, an inhibitor of mitochondrial respiratory chain, on ionic currents and miniature end-plate potential in mouse hippocampal (mHippoE-14) neurons. Cell Physiol Biochem 47:330-343. https://doi.org/10.1159/000489810

23. Shiga H, Taki J, Okuda K, Watanabe N, Tonami H, Nakagawa H, Kinuya S, Miwa T (2017) Prognostic value of olfactory nerve damage measured with thallium-based olfactory imaging in patients with idiopathic olfactory dysfunction. Sci Rep 7:3581. https://doi. org/10.1038/s41598-017-03894-4

24. Huisman E, Uylings HB, Hoogland PV (2004) A 100\% increase of dopaminergic cells in the olfactory bulb may explain hyposmia in Parkinson's disease. Mov Disord 19:687-692. https://doi.org/10. 1002/mds. 10713

25. Betarbet R, Sherer TB, MacKenzie G, Garcia-Osuna M, Panov AV, Greenamyre JT (2000) Chronic systemic pesticide exposure reproduces features of Parkinson's disease. Nat Neurosci 3:1301-1306. https://doi.org/10.1038/81834

Publisher's Note Springer Nature remains neutral with regard to jurisdictional claims in published maps and institutional affiliations. 